\title{
El Tiempo en la Poesía de Ricardo Jaimes Freyre
}

Característica de la poesía de Jaimes Freyre, aunque no claramente $($ expresada, es la preocupación temporal. En verdad, su poder y su fuerza se deben, en gran medida, a esta sutileza de su pensamiento, a estar implícita esta preocupación en la confrontación dramática entre el instante que pasa -el momento transitorio, huidizo del presente- y los eternos momentos, de todos los tiempos. Es decir que surge de la confrontación entre lo temporal y lo permanente. $\mathrm{Y}$ aquí cabe bien recordar lo que dijera Unamuno:

...vuelvo a repetirlo: es dentro y no fuera donde hemos de buscar al hombre. Eternismo y no modernismo es lo que quiero; no modernismo que seria anticuado y grotesco cuando la moda pase. ${ }^{1}$

Y lo que Antonio Machado, el gran poeta del 98, dijera:

La poesía moderna, que, a mi entender, arranca, en parte al menos, de Edgar Poe, viene siendo hasta nuestros días la historia del gran problema que al poeta plantean estos dos imperativos, en cierto modo contradictorios: esencialidad y temporalidad.2

Porque tampoco hay poesía sin ideas, sin visiones de lo esencial. ${ }^{3}$

Estas citas muestran no solamente una básica diferencia entre el espítitu del 98 y el del Modernismo, sino que también señalan y dan énfasis a la gran preocupación del 98: el paso del tiempo y la permanencia de los valores.

1 En "Prologal", Ensayos (Madrid: Aguilar, vol. 2).

2 En "Poética", Poesías completas (Madrid: Espasa, 1960), pp.20-21.

3 ibidh, p. 21. 
Ahora bien: al tratar el tema del fugit irreparabile tempus, Jaimes Freyre - considerado hasta ahora uno de los modernistas más señalados y más típicos- se aleja grandemente de este grupo, grupo que, como bien sabido está, tiende a exaltar el presente momentáneo en toda la alegría y la vitalidad de la realidad, de la presencia de la vida.
¡Amar! ¡Reír! La vida es corta, gozar de abril es lo que importa. ${ }^{4}$
En el reino de mi aurora
no hay ayer, hoy ni mañana;
danzo las danzas de ahora
con la música pagana. ${ }^{5}$

repite Darío, exaltando el valor del momento que pasa. Nótese que no solamente parece asignar un valor total al momento instantáneo del presente, sino también a un fenómeno igualmente pasajero: al placer. Lo cual es una actitud típicamente modernista.

No muy diferente en esencia es el sentimiento que expresa Jaimes Freyre en las siguientes líneas; lo distinto en ellas es la actitud, y el tono. La urgencia se da no al instante que pasa ni al placer que trae consigo, sino a la nostalgia de los tiempos idos:

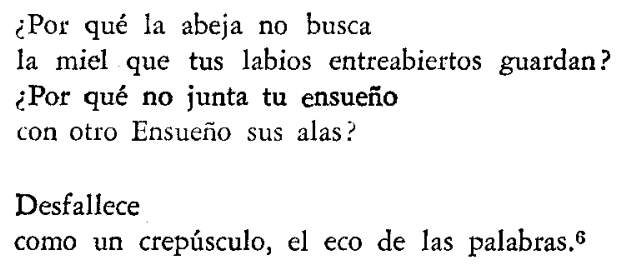

El énfasis cae exactamente en el punto opuesto al del Modernismo; es decir en lo efímero del placer. Así que, en vez de decir Don Darío "gozar de abril es lo que importa", Jaimes Freyre dirá:

La sangre en las rosas no dura siempre y las rosas se apagan, dibuja junto a los labios un surco la risa amarga; los ojos y las mejillas son caminos de las lágrimas.

4 "Dezir", Prosas profanas, 1896.

5. "El clavicordio de la abuela", Poema del Otoño y otros poemas, 1910.

6 "Voz extraña", País de sueño, Castalia Bárbara, 1897. 
En tu cuerpo,

donde el triunfo de la curva la suma Belleza exalta, pondrá el Invierno sus hielos

mañana.

¡Oh, el calor de las caricias!

¡Oh, los besos!...

Desfallece

como un crepúsculo, el eco de las palabras.7

Grande es la diferencia entre Ricardo Jaimes Freyre y los modernistas. Aun en los momentos en que éste describe un instante de placer, pasa, rápido, el sentimiento de su fugacidad y de su insubstancialidad:

Sangre de las venas de las rosas rosas

baña las mejillas, purpura los labios...

en las fugitivas horas voluptuosas

hay fuego en las venas de las rosas rosas. 8

fugitivo como una alegria

dulcemente en mi oído resuena. ${ }^{9}$

al mismo tiempo que el sentimiento de nostalgia -la nostalgia por el tiempo ido- está siempre presente, cualquiera que sea el tema:

La pálida nostalgia de las brumas

te envuelve joh reina desterrada y triste!

¡la pálida nostalgia de las brumas!10

Ábrase así a tus ojos el pavoroso Arcano, mientras mis pasos llevo por entre el bosque humano, soñador y nostálgico y triste hasta la muerte...11

Y nótese que esta última estrofa proviene de un poema que se llama "El poeta celebra el goce de la vida".

La última línea, "soñador y nostálgico y triste hasta la muerte", parece haber tenido repercusiones, o es quizás común en la poesía. Tal es el caso de Francisco Villaespesa:

7 Id.

8 "Canción de primavera", País de sueño, Castalia Bárbara, 1897.

9 "El Canto del Graal", ibíd.

10 "De la Thule lejana", ibid.

11 "El poeta celebra el goce de la vida", Pais de sombra, Castalia Bárbara, 1897. 
Nada me alegra y nada me divierte iY en medio de las fiestas de la vida mi corazón va triste hacia la Muerte!

en su "Tedium Vitae", que es de 1912,12 o de Arturo Torres-Ríoseco:

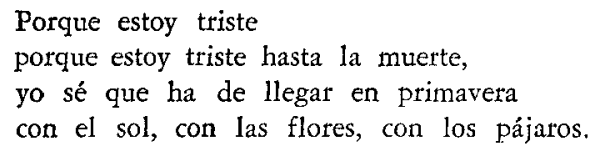

en su "Ha de venir un día", que es de 1921.13

La semejanza es interesante porque entre los poetas modernistas españoles Villaespesa era el que mejor conocía a los hispanoamericanos. E. Diez Canedo así lo menciona, ${ }^{14}$ como también Juan Ramón Jiménez. ${ }^{15}$

Más tarde, Jaimes Freyre expresará el pasar del tiempo en tonos mucho más angustiados, que tienen de modernistas solamente las innovaciones del verso:

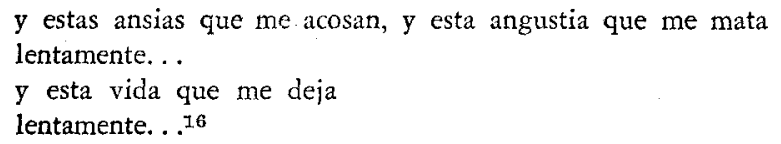

La realidad es evanescente. El tiempo lo destruye todo. Pero el poeta trata de encontrar algo a qué aferrarse, algo permanente: la esencia de las cosas. Trata de definir la esencia de las cosas, hasta de las más efímeras. Hay un poema que expresa muy bien esta idea - cuando al buscar la esencia de las cosas, logra por fin definirla: es "Lo fugaz".

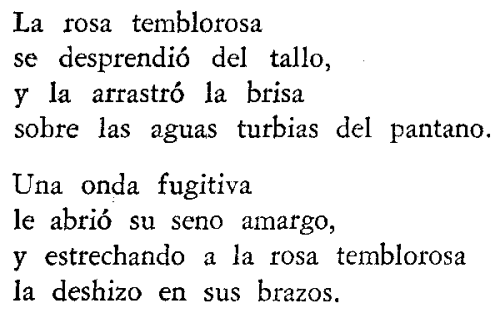

12 Jardines de plata (Madrid, 1912).

13 En el encantamiento (Costa Rica, 1921).

14 En "Los comienzos del modernismo en España", España (Madrid: 21 de julio de 1923).

15 En El Modernismo. Notas de un curso (Aguilar, 1962).

16 "Sublimar", Los sueños son vida, 1917. 


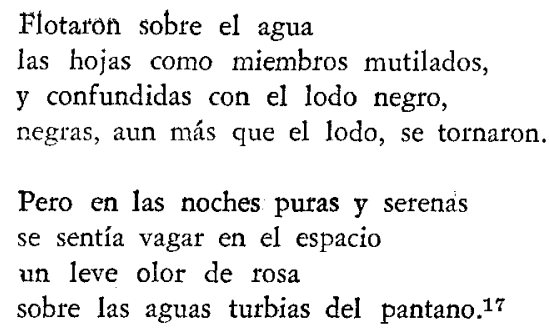

El ejemplo de este poema sirve para ilustrar lo que es típico del pensamiento de Jaimes Freyre, y de la estructura de sus poemas. El poema es hasta tal punto personal y profundamente intelectual que, a menos de leérselo cuidadosamente, se corre el riesgo de ver en él solamente la simple descripción de una ocurrencia corriente.

En realidad, el poema consiste de dos poemas: uno que narra la anécdota, el otro que expresa la idea. Este procedimiento, que Jaimes Freyre utiliza constantemente, es característicamente suyo: la idea es siempre general y universal, y, al mismo tiempo, simple y concreta. $Y$ el poeta deja al lector la libertad de escoger la significación del poema de acuerdo con los dictados de su propia identidad.

En este caso particular, el lector tiene que decidir el sentido que ha de dar a la rosa, y al pantano. La rosa, según quien la mire, podría significar la poesía (o el arte), o la belleza, o el amor, en fin, cualquier cosa. El pantano entonces podría ser el hastío, el cansancio, la brutalidad de la existencia, la vida misma vista como desilusión, como la suma de bajas pasiones, de crueles desencantos; como pobreza, enfermedad, tristeza, fracaso. O quizás podría ser todo esto junto, poco importa. El pensamiento del poeta, como la estructura de una proposición matemática, conserva su validez, cualquiera que sean los valores que sirven para sustituir los términos de la ecuación. Y aquí conviene hacer notar que este poeta no solamente trabaja tanto y tan bien el poema que cuanto más se lo observa más bellezas se le encuentran, sino que pone el mismo cuidado en pulir la idea. En este sentido se parece a Valery, a quien los estudios matemáticos comunicaton el amor por la expresión justa y la palabra adecuada.

"La rosa temblorosa", es decir la belleza perfecta, frágil y delicada (o el amor, que es perfecta belleza, delicada y frágil) ha sido arrancada por una brisa pasajera (perdida: en un momento de descuido y de inconsciencia) para caer en "las aguas turbias del pantano". "La brisa" puede consistir de cualesquier actos que traigan la desilusión o el desengaño;

17 "Lo fugaz", id. 
el pantano, ya se ha dicho, puede ser la miseria, o el tedio, o el temor, o según la moda, la angustia.

Y es así como el amor, o la belleza, o la ilusión, bajo la forma de los destrozados pétalos, "confundidas con el lodo negro", "negras, aun más que el lodo, se tornaron". Y, sin embargo, más tarde, "en las noches puras y serenas", el tenue recuerdo del amor y del ensueño cubre las turbias aguas de nuestro diario vivir con el perfume delicado de la rosa.

Claro es el pensamiento, y exactas las imágenes. $Y$ lo que distingue al poema es la libertad en la distribución de los versos, y la rima, de efecto extraordinariamente musical.

Lo que distingue a la mayor parte de la obra poética de Jaimes Freyre es la musicalidad de su forma y la originalidad de su contenido. Al mismo tiempo es interesante observar que todos sus poemas surgen de la confrontación de dos elementos, solamente dos (y es esta simplicidad básica a la que se debe, en gran parte, su superioridad): la realidad y las ideas. Es decir que su poesia emplea lo que el pintor Paul Klee ha denominado "las realidades del arte": les realités de l'art qui font la vie un peu plus haute qu'elle ne semble l'être communément. ${ }^{18}$

"Lo fugaz" es poema de un simbolismo particularmente hermoso. Pues es la esencia de la rosa, lo que es substancial en ella, lo que persiste: la belleza esencial, lo más íntimo, lo inefable, lo que no puede ser captado: su perfume. Mientras que la belleza superficial, la aparente, la externa, ha sido completamente destruída.

Hay un cubano, poeta que murió a los veintiséis años, que parece haber copiado este poema. Se llama René López (1882-1909), y su madrigal dice:

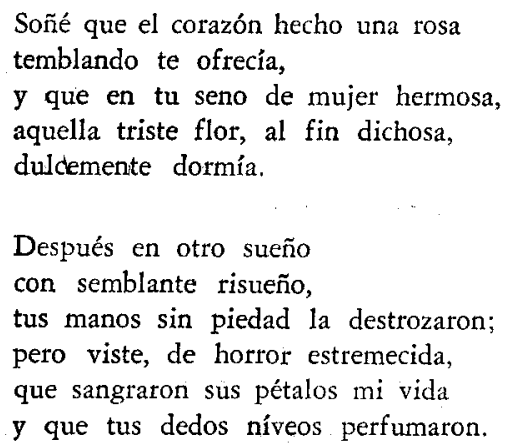

18 Liens (París, noviembre de 1963, No. 127, p. 2)... 
El tema, la idea, el vocabulario, hasta la rima es casi la misma. Lo que pasa es que López, que no era gran poeta, carece de la seguridad, de la fluidez, del toque mágico de Jaimes Freyre. Esste publicó su libro en 1897, cuando López tenía menos de catorce años. Lo curioso es que Max Hentíquez Ureña no se diera cuenta de ello, y dijera que López tiene "alguna novedad ideológica". 19

La rosa puede servir para ilustrar el hecho, tan repetido en literatura, del modo en que una imagen muy simple asume o es capaz de asumir significados completamente contradictorios según quien la use. Basta citar el caso de tres poetas modernistas para demostrar la aserción. Rubén Darío, el poeta sudamericano, usa la rosa para representar un tema constantemente repetido a través de su pocsía: la importancia del placer.
Celebrad prestigiosas Scheherezadas
llenas de hechizos miliunanochescos;
dad vuestros versos a huries y hadas
o a reinas de otros reinos pintorescos.
Noble visión hay en templos y frescos
para loor de mil divinas cosas
que se han vivido o se han imaginado;
más nada que a esto sea comparado:
la sencillez de las perfectas rosas. ${ }^{20}$

que es también el valor simbólico que le da el Valle-Inclán modernista.

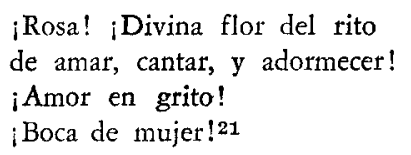

Para ellos representa el placer instantáneo, el del momento, el único a ser tomado en consideración. Más tarde, el Valle-Inclán de los esperpentos llegará a las sutilezas de "La rosa de papel", para desembocar en los dolorosos retorcimientos de sus rosas poéticas en su Claves líricas. Llegará a la cumbre en "La Rosa deshojada", que es la que no existe. Pero de esto hablaré en otra ocasión.

Pues de lo que se trataba en estas páginas era de mostrar la manera en que, en la poesía de Ricardo Jaimes Freyre, la rosa representa la bre-

19 Breve bistoria del Modernismo (México: Fondo de Cultura Económica, 1962), pp. 424-25.

20 "Balada sobre la sencillez de las rosas perfectas" $R$. Dario. Poesias (México: Fondo de Cultura, 1952), p. 465.

21 "Claves líticas, Opera Omnia (Madrid: Aguilar, 1958), pp. 1226-27. 
vedad de la vida en oposición a la cualidad transcendental de la belleza: la condensación de la eternidad en el instante que pasa. Es decir, su actitud es la de la consideración de lo transitorio en cuanto reflejo de la esencia y de lo permanente.

University of California, Mireya Jaimes-Freyre

Santa Barbura 